\title{
Endothelial cell bacillation in lepromatous leprosy: a case report
}

\author{
A MUKHERJEE* \& W M MEYERS $\dagger$ \\ Armed Forces Institute of Pathology, Washington DC 20306-6000, \\ USA
}

\section{Accepted for publication 20 May 1987}

\begin{abstract}
Summary We report observations on a biopsy specimen of skin from a lepromatous leprosy (LL) patient with heavy bacillation of vascular endothelial cells. The staining properties of the bacilli in the endothelial cells when compared to those in the surrounding macrophages suggest that endothelial cells may be preferential sites for growth of Mycobacterium leprae.
\end{abstract}

\section{Introduction}

Acid-fast bacilli (AFB) in the endothelium of blood vessels in lepromatous patients has been a subject of interest for many years. ${ }^{1-6}$ Most observers now accept that, like macrophages and Schwann cells, endothelial cells are heavily and persistently bacillated in polar lepromatous lesions. The fate of AFB in vascular endothelial cells and the role of the bacillated endothelium in the evolution of granulomas remain unclear. We recently reviewed a biopsy specimen of skin from a patient with active lepromatous leprosy with interesting findings related to heavy bacillation of the endothelial cells of blood vessels. Histological and ultrastructural features are presented.

\section{Case report}

The biopsy specimen was from the left forearm of a 61-year-old Mukongo man from Zaire. The patient stated that the disease began 6 months prior to biopsy, and there was no history of specific antileprosy therapy. At biopsy, the patient had innumerable vague coppery macules over much of the body with thickening of the skin of the ears, nose and upper lip, and nodules over the left wrist and right elbow. The ulnar, radial cutaneous and common peroneal nerves were thickened, and there was loss of sensation over both plantar surfaces.

The single 6-mm punch biopsy specimen was bisected and fixed for both light and electron microscopy. For light microscopy, tissue was fixed in $10 \%$ buffered formalin, processed and embedded in paraffin, and 5- $\mu$ sections stained with hematoxylin-eosin and Fite-Faraco stains. For

* Present address: Institute of Pathology, ICMR, PO Box 4909, New Delhi 110029, India.

+ Correspondence and requests for reprints. 


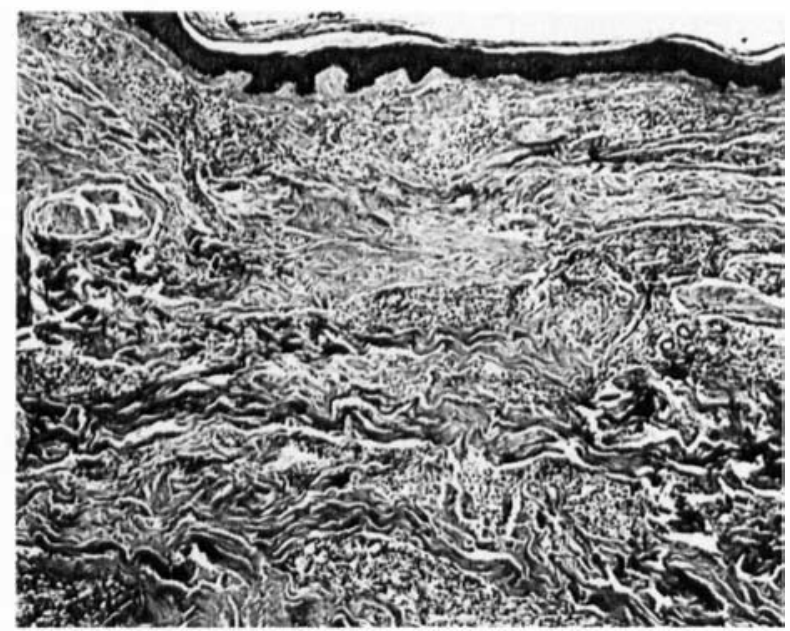

Figure 1. Skin of patient studied showing lepromatous infiltrations that consisted largely of vacuolated macrophages in the dermis. (H\&E original $\times 60$.) (AFIP neg. 87-5210.)

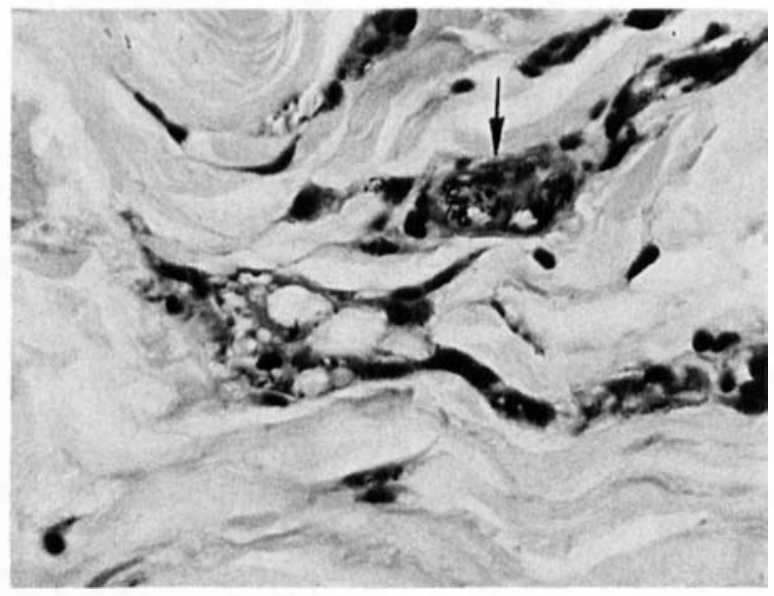

Figure 2. Oil-immersion photomicrograph of Figure 1, showing acid-f ast bacilli in a dermal blood vessel (arrow) and in dermal macrophages. The organisms in the endothelium of blood vessels are mostly solid-staining while those in the macrophages are mostly beaded. (Fite--Faraco original $\times 600$.) (AFIP neg. 87-5208.)

electron microscopy, tissue was fixed in formol-glutaraldehyde, post-fixed in osmium tetroxide, processed and embedded in Spurr's low-viscosity resin. Ultra-thin sections from blocks with adequate cellular infiltrations, as demonstrated in toluidine blue-stained semi-thin sections, were cut with diamond knives and stained with uranyl acetate and lead citrate before examination with a Zeiss EM109 electron microscope.

Light-microscopic examination revealed that about $20 \%$ of the dermis was occupied by lepromatous infiltrates in the superficial and mid-dermis (Figure 1). These infiltrates consisted of clusters of coarsely vacuolated macrophages mixed with a few lymphocytes. Fite-Faraco stain revealed large numbers of AFB in macrophages, nerves and vascular endothelial cells. The organisms were in loose clusters and in globi. 


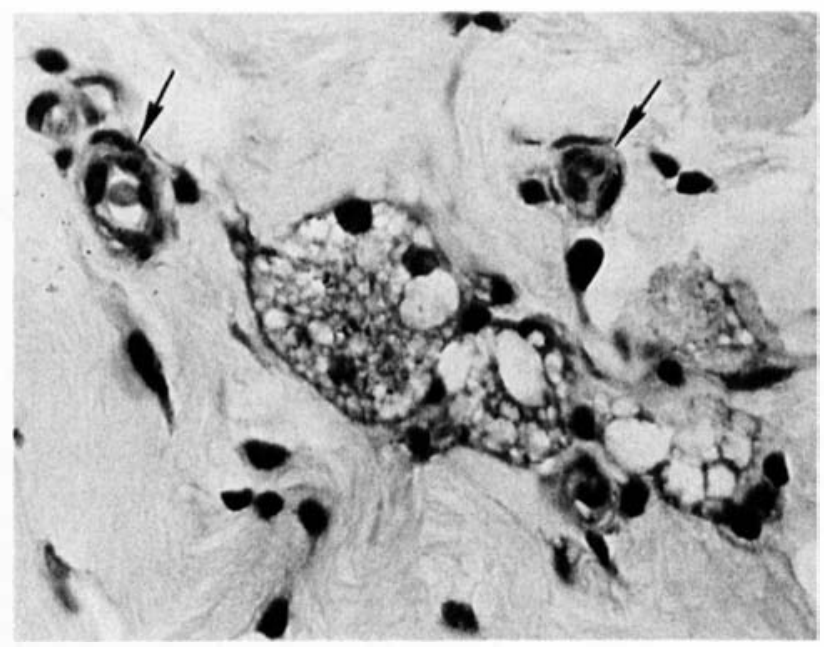

Figure 3. Oil-immersion photomicrograph from another area of section shown in Figure 1 showing two dermal blood vessels (arrows) and a large vacuolated macrophage. Note differences in staining properties of acid-fast bacilli at the two sites. (Fite-Faraco original $\times 600$.) (AFIP neg. 87-5209.)

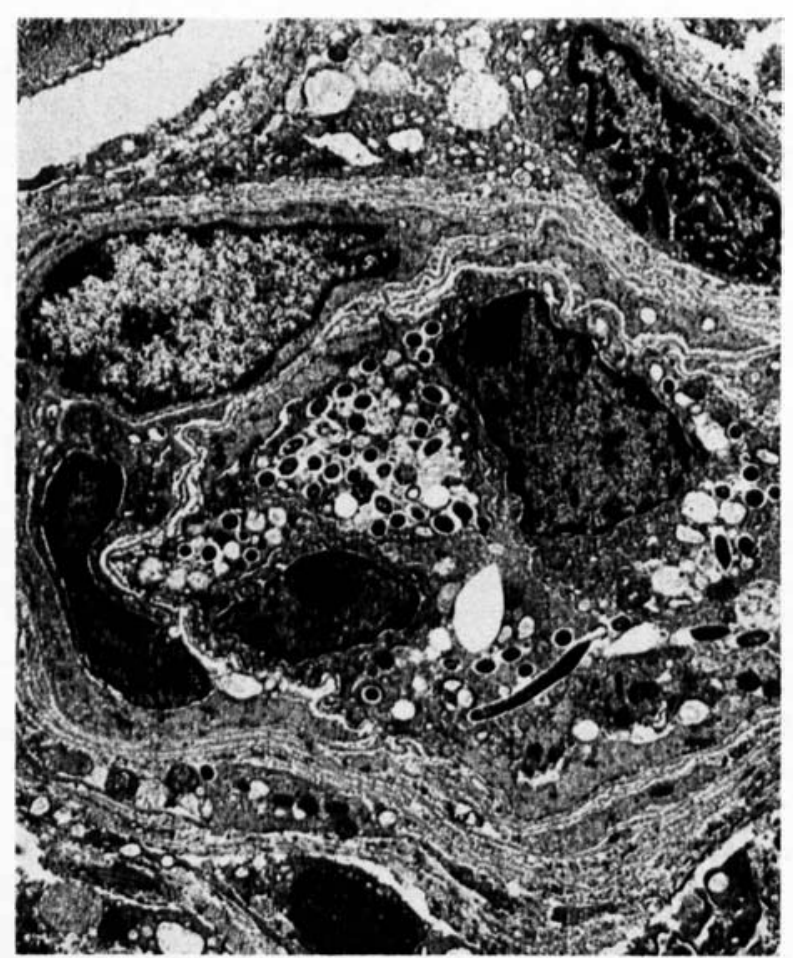

Figure 4. Electron micrograph of a dermal blood vessel. There are numerous solid organisms in both the endothelial cell cytoplasm and in the vessel lumen. The bacillus cut in longitudinal section is in the vessel lumen. (Uranyl acetate and lead citrate original $\times 7,500$.) (AFIP neg. 87-5206.) 


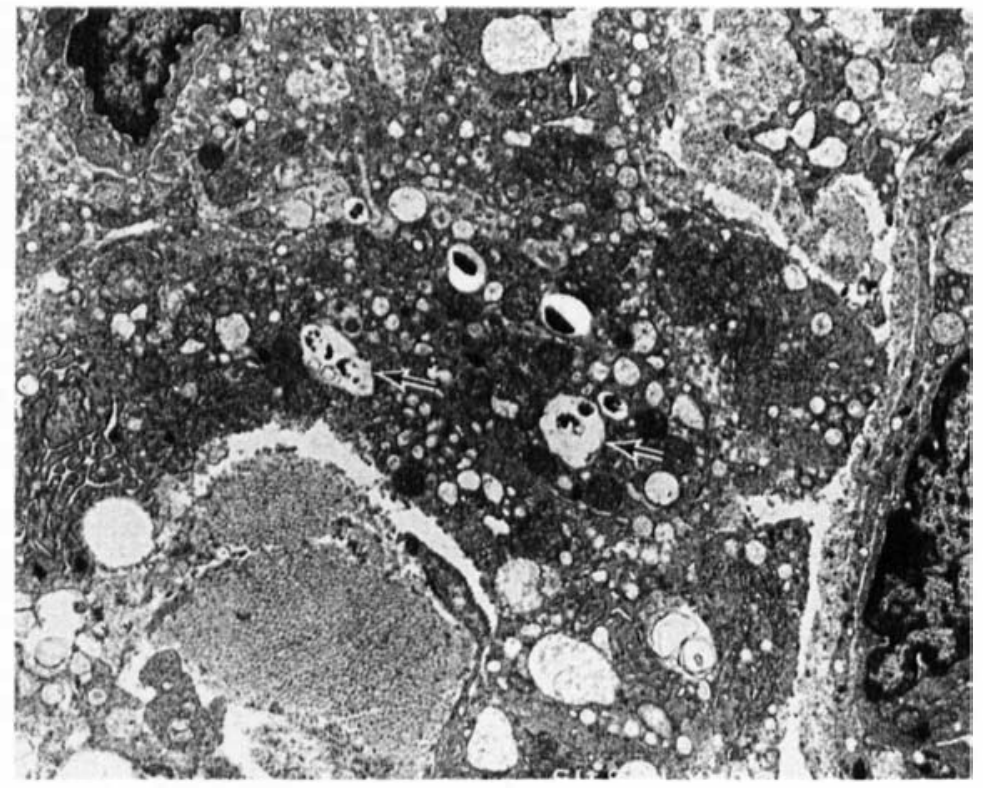

Figure 5. Electron micrograph of a dermal macrophage located near the blood vessel seen in Figure 4. There are both solid and fragmented forms (arrows) in the macrophage cytoplasm. (Uranyl acetate and lead citrate original $\times 7,500$.) (AFIP neg. 87-5207.)

The striking feature in this lesion was the marked difference in the staining properties between the AFB in the endothelial cells and those in the surrounding macrophages and nerves (Figures 2 and 3). Thus, a remarkably high percentage of the organisms in the endothelial cells were solidstaining while fragmented AFB predominated in macrophages and nerve twigs. Morphologic indices (MI) of AFB in each small cluster of cells with a bacillated blood vessel in it were estimated on the histological section. The results revealed an approximate 10 -fold difference between the proportion of well-stained bacilli in the vascular endothelium compared to those in adjacent macrophages. There was no difference in the MI of the AFB in the superficial and deeper layers of the dermis.

Electron-microscopic (EM) examination confirmed the differences in the morphologic indices in endothelial cells and macrophages (Figures 4 and 5). Multiple blocks were sectioned from the processed tissue, and all the grids examined showed a persistently high degree of endothelial cell bacillation with free organisms in the capillary lumina in about $60 \%$ of blood vessels in the cellular infiltrations. Although most of the bacilli in the EM sections were cut in cross-section, nearly all of the organisms in the endothelial cells had uniformly staining cytoplasm and intact cell walls. In contrast, fragmented bacilli predominated in macrophages in the immediate perivascular area, and in the nerves.

\section{Comment}

The staining characteristics of Mycobacterium leprae both in tissues and in smears reflect the state of viability of the organism. Thus, organisms staining as solid rods in the Fite-Faraco stains and as uniformly stained electron-opaque structures with intact cell walls in electron micrographs of thin sections are regarded as viable. However, those that are fragmented, beaded or granular by the Fite-Faraco stain, and with irregular electron opacities, and electron-lucent areas in the cytoplasm, 
or incomplete or fragmented cell walls in electron micrographs, are considered non-viable. ${ }^{7.8}$ We observed a clear-cut difference between the bacilli in the endothelial cells and those in the macrophages, with many more solid forms in endothelial cells by both light- and electronmicroscopic examinations. Although there have been several reports on the frequency and degree of endothelial cell bacillation, we are not aware that this aspect of the lepromatous lesion, i.e. the higher MI in the blood vasculature endothelium, has been highlighted before. Incidentally, in this patient we did not observe a higher MI in the lepromatous infiltrations in the superficial zone of the dermis, i.e. near the epidermis as had been reported. ${ }^{9}$

Metabolic requirements of the leprosy bacillus may explain why the percentage of solid-staining (and, hence, viable) organisms is higher in the endothetium of blood vessels. In vitro studies on the metabolism of $M$. leprae indicate the following: (i) respiration in $M$. leprae is mediated through the cytochrome system with oxygen as the final electron acceptor; ${ }^{10}$ (ii) a complete tricarboxylic acid cycle is operative in $M$. leprae $;^{11.12}$ and (iii) production of ATP by $M$. leprae requires oxygen. ${ }^{13}$ These observations make the availability of oxygen an important factor in the growth and viability of this bacterium. Amongst the various cells parasitized by $M$. leprae in the lepromatous lesion, the blood vessel endothelial cell most likely has the highest $\mathrm{pO}_{2}$ because of its proximity to circulating blood. Another factor that may be operative is that, unlike macrophages, endothelial cells have no known bactericidal mechanism and have not been shown to develop such mechanisms upon stimulation by lymphocyte products. In fact, in a larger study of the ultrastructure of bacillated endothelial cells in leprosy, we have not observed any evidence of bactericidal activity in the vascular endothelium.

Our findings emphasize the importance of blood vessels in lepromatous infiltrations and indicate that the vascular endothelium can be a preferential site for growth of $M$. leprae. Our experience in the histopathologic evaluations of large numbers of biopsy specimens from lepromatous leprosy patients suggests that the differential staining of $M$. leprae in endothelial cells and macrophages is a common phenomenon. We believe, however, that a larger study designed specifically to investigate this point is warranted.

\section{Acknowledgments}

We thank Dr K. Russell and Cit. Madituka, Institut Medical Evangelique, Kimpese, Zaire, for contributing the formalin-fixed and glutaraldehyde-fixed biopsy specimens. AM was supported by a Fogarty Fellowship from the National Institute of Health, Bethesda, Maryland, USA during this study. This study was supported partially by grants from the American Leprosy Missions, DamienDutton Society for Leprosy Aid, and The Leprosy Mission International.

\section{References}

${ }^{1}$ Fite GL. The vascular lesions of leprosy. Int J Lepr, 1941; 9: 193.

2 Mitsuda K. Atlas of leprosy. Okayama, Japan: Chotokai Foundation, 1952, page 20.

${ }^{3}$ Coruh G, McDougall AC. Untreated lepromatous leprosy: Histopathologic findings in cutaneous blood vessels. Int J Lepr, 1979; 47: 500.

4 Turkel SB, VanHale HM, Rea TH. Ultrastructure of the dermal micro-vasculature in leprosy. Int J Lepr, 1982; 50: 164.

5 Burchard GD, Bierther M. An electron microscopic study of the small cutaneous vessels in lepromatous leprosy. Int J Lepr, 1985; 53: 70.

${ }^{6}$ Mukherjee A, Misra RS, Sharma AK. Ultrastructure of leprous phlebitis. Int J Lepr, 1985; 53: 571.

7 Waters MFR, Rees RJW. Changes in the morphology of Mycobacterium leprae in patients under treatment. Int J Lepr, 1962; 30: 266.

${ }^{8}$ Rees RJW, Valentine RC. The appearance of dead leprosy bacillus by light and electron microscopy. Int $J$ Lepr, 1962; 30: 1 .

9 Girdhar BK, McDougall AC. The morphology of bacilli at different levels of dermal infiltrate in lepromatous leprosy. Int J Lepr, 1982; 50: 477. 
10 Ishaque M, Kato L, Skinsnes OK. Cytochrome-linked respiration in host-grown M. leprae isolated from an armadillo (Dasypus novemcinctus, L.). Int J Lepr, 1977; 45: 114.

11 Wheeler PR. Oxidation of carbon sources through the tri-carboxylic acid cycle in Mycobacterium leprae grown in armadillo liver. J Gen Microbiol, 1984, 130: 381.

12 Wheeler P. Metabolism in Mycobacterium leprae: Its relation to other research on M. leprae and to aspects of metabolism in other mycobacteria and intracellular parasites. Editorial. Int J Lepr, 1984; 52: 208.

13 Heine HS, Veras JR, K vach JT. Determination of physiology and metabolic requirements of Mycobacterium le prae by monitoring changes in adenosine triphosphate levels. Abs Ann Meet Amer Soc Microbiol, 1986, p. 124.

NEWS AND NOTES

\section{The Heiser Program for Research in Leprosy}

Beginning postdoctoral research fellowships, research grants, and visiting research awards available in amounts up to $\$ 19,000$ per year, plus other allowances. Applicants should have MD, PhD, or an equivalent degree. Applications by 1 February 1988, for awards to be activated June to December 1988. For information, write to: The Heiser Program, 450 East 63rd Street, New York, NY 10021.

\section{Retirement of Dr R H Thangaraj, The Leprosy Mission International, Southern Asia}

Dr R H Thangaraj has now retired as TLMI Director in Southern Asia. However Dr (Mrs) E S Thangaraj will continue her work as Medical Coordinator and will still supervise the distribution of literature.

Please note that all correspondence and orders from India for Teaching and Learning Materials should be addressed to: Dr (Mrs) Thangaraj, Medical Coordinator, The Leprosy Mission, Salur 532 591, Vizianagram District, Andhra Pradesh, India. 